\title{
Projeto político-pedagógico da escola: o elemento essencial do trabalho do coordenador pedagógico
}

\author{
Political-Pedagogical Project of the school: the essential element of the work \\ of the pedagogical coordinator
}

Doutora em Educação pela Universidade Federal de Goiás. Docente da Faculdade Araguaia, Goiânia, GO - Brasil. liviabrisolla@gmail.com

Norivan Lustosa Lisboa Dutra Doutoranda em Educação pela Universidade Federal de Goiás. Docente do Instituto Federal de Brasília, Brasília, DF - Brasil. nori.dutra@gmail.com

\begin{abstract}
Resumo: Essa pesquisa tem como foco discutir as contribuições do Projeto Político-Pedagógico (PPP) para o trabalho de coordenador pedagógico. O texto encontra-se organizado em três momentos, a saber: função social da escola; PPP na perspectiva da gestão democrática; o que dizem os coordenadores pedagógicos e os projetos políticos-pedagógicos: atribuições e metas. Destarte, abordam-se as seguintes questões: o que representa o PPP para o trabalho do coordenador pedagógico frente a um processo de gestão democrática? O que dizem os documentos e as coordenadoras pedagógicas sobre suas atribuições e metas? A partir das reflexões e da análise documental, evidencia-se que, para o PPP se tornar o elemento essencial do trabalho do coordenador pedagógico, é preciso maior clareza e conscientização de suas atribuições num processo de trabalho coletivo de (re)construção do PPP.
\end{abstract}

Palavras-chave: Projeto político-pedagógico. Coordenador pedagógico. Escola. Gestão democrática.

Abstract: This research focuses on the contributions of the Political-Pedagogical Project (PPP) to the work of pedagogical coordinator. The text is organized in three moments, namely: social function of the school; politicalpedagogical project in the perspective of democratic management; what pedagogical coordinators and politicalpedagogical projects say: attributions and goals. Thus, the following questions are addressed: what is the politicalpedagogical project for the pedagogical coordinator's work which faces a democratic management process? What do documents and pedagogical coordinators say about their assignments and goals? From the reflections and the documentary analysis, it is evident that, for the political-pedagogical project to become the essential element of the work of the pedagogical coordinator, it is necessary to have greater clarity and awareness of its attributions before a process of collective work of (re) construction of the political-pedagogical project.

Keywords: Political-pedagogical project. Pedagogical coordinator. School. Democratic management. 


\section{Considerações iniciais}

A sociedade contemporânea vive constantes mudanças de ordem social, econômica, científica, cultural e tecnológica que não podem ser negligenciadas pela educação. São muitos os desafios enfrentados pelo coordenador pedagógico (CP), entre eles: dificuldade de implementar uma gestão democrática, compreensão das necessidades daqueles que atuam na escola, bem como do seu papel e de suas atribuições no contexto escolar.

Considerando-se tais desafios é indispensável que o coordenador pedagógico, a equipe de professores e os membros da comunidade construam uma prática pedagógica crítica e emancipatória que permita ao estudante questionar, discutir alternativas, fazer escolhas, tomar decisões, avaliar as suas consequências e, sobretudo, ser capaz de descortinar as tensões sociais. Tal processo exige que esse profissional desenvolva "continuamente uma leitura próxima de sua realidade e dos atores sociais que compõem e vive o savoir-faire" (saber-fazer) (LIMA; SANTOS, 2007, p. 78). A leitura contínua da realidade, como ação complexa, envolve amplo olhar ao universo educacional, considerando o contexto social, político, econômico e cultural, as concepções pedagógicas, a função social da escola, a formação contínua, o currículo e as práticas pedagógicas. Cabe salientar que, nesse processo de leitura, insere-se o PPP, que não pode ficar de fora.

Assim, tanto o trabalho de coordenação pedagógica quanto as ideias expressas no PPP são idealizados a partir da cultura, da concepção formativa e dos objetivos educacionais que se pretende alcançar. Por isso, constituem um poderoso instrumento político e pedagógico de integração dos conteúdos, conceitos, experiências e questionamentos para transformar a escola em um espaço crítico de debate dos problemas, dificuldades e possibilidades. Esse espaço inexiste sem a participação ativa de todos os profissionais da educação, da comunidade e da família.

É, portanto, nessa linha, que a presente discussão se insere. O objetivo é refletir o PPP da escola como elemento central do trabalho do coordenador pedagógico, sobretudo na organização do trabalho pedagógico (OTP), para que se possa alcançar um trabalho que preze pela qualidade do processo de ensino-aprendizagem. Importa salientar que o compromisso educacional de uma formação para a consciência crítica fica prejudicado se a escola não entender a essencialidade do PPP para o desenvolvimento eficaz do trabalho do coordenador pedagógico. Esse documento explicita os objetivos, os fundamentos teórico-metodológicos, o tipo de organização e as formas de implementação e avaliação da escola (VEIGA, 2004). 
Trata-se de um estudo de abordagem qualitativa que se utiliza da entrevista semiestruturada com três coordenadoras pedagógicas que atuam em escolas públicas do Distrito Federal. Essa estratégia teve como intuito saber o que pensam essas profissionais sobre o PPP da escola em que atuam e sobre suas atribuições como coordenadoras pedagógicas. A partir daí, realizou-se a análise documental, considerando os PPPs de cada escola em que essas profissionais trabalham, além da Lei de Diretrizes e Bases da Educação Nacional (LDB) e do artigo $6^{\circ}$ da Portaria n. 29 de 06 de fevereiro de 2006, da Secretaria de Estado de Educação do Distrito Federal.

O texto foi organizado em etapas, sendo a primeira uma reflexão da função social da escola, seguida de uma discussão sobre o PPP na perspectiva da gestão democrática. Por fim, apresentamos os resultados da investigação, levando-se em conta a fala dos coordenadores pedagógicos e a relação desses profissionais com o PPP.

\section{Função social da escola}

Na sociedade capitalista em que vivemos, não há como separar a educação do contexto social, político, cultural e econômico. A escola assume a função de propagar e reproduzir a força de trabalho que advém das relações de produção, segundo os interesses do capital. A escola, como meio de reprodução das relações de produção, necessariamente reproduz a dominação e exploração (FREITAS, 1995) e, ao assumir tal função, descreve também as desigualdades sociais e as relações de poder.

Historicamente, a escola de hoje é fruto de um modelo taylorista/fordista de produção capitalista que, ancorado na teoria pedagógica tecnicista, levou as atividades, os PPPs, os currículos, os processos avaliativos e o trabalho do coordenador pedagógico a primarem por um controle. É nesse contexto que se sustenta uma sociedade baseada no autoritarismo, no individualismo, na fragmentação e na exclusão social.

Os pressupostos neotecnicistas ainda sustentam e conduzem o projeto educativo de muitas escolas brasileiras. A instituição educacional, "se ninguém exercer pressão contra, é reprodutivista. As possibilidades não são um produto 'natural'. São concretizadas no bojo das lutas político-ideológico e só se convertem em realidade com clareza política e ideológica" (FREITAS, 1995, p. 277). A educação pode trabalhar na contramão dessa concepção alienante, como instrumento de luta contra a divisão fragmentada do trabalho e do controle hierárquico. A 
escola também manifesta, em sua organização, relações, concepções e objetivos sociais permeados de limites e possibilidades. Deste modo, eco as contradições desse universo complexo.

A organização do trabalho pedagógico da escola não deixa de lado as dinâmicas e prerrogativas operacionais que dizem respeito às funções da escola. Freitas (1995) destaca que a escola não é uma "ilha" isolada da sociedade, contudo, é densamente influenciada por ela, e chamada a assumir os objetivos produzidos em seus contornos. A escola não é inteiramente determinada pela organização social, mas também não é completamente liberta de suas amarras.

Por mais que a instituição educacional esteja inserida nessa conjuntura reprodutivista, não significa que sua perspectiva política, pedagógica, social, cultural e filosófica não possa caminhar na direção contrária, com ações educativas integradoras e democráticas. Por essa razão, outras formas de OTP da escola têm conduzido as reflexões em direção à democratização do espaço escolar, com a valorização e participação das pessoas da comunidade escolar por meio do diálogo crítico dos anseios, das problemáticas e dos desafios impostos pela atualidade do contexto social para a construção do PPP. O trabalho do coordenador pedagógico insere-se nos contextos políticos e socioculturais, o que significa ser necessário que se compreenda que a escola sofre as determinações sociais e exerce uma função social.

É justamente aí que o PPP se torna um elemento vital para a realização de mudanças da função social da escola em direção oposta aos processos individualistas, autoritários, fragmentados e de exclusão. Além disso, muitos são os desafios dessa escola capitalista, como: tecnologia, reprovação, evasão e falta de condições de trabalho.

Urge aqui encontrar os caminhos para a superação desses desafios e promover a transformação da realidade. Trata-se de conceber as mudanças necessárias à escola dentro de um processo reflexivo, dinâmico e analítico de uma gestão democrático-participativa, com um PPP que amplie o olhar para além do pedagógico. A escola é espaço de possibilidades e formação humana.

\section{$3 \mathrm{O}$ projeto político-pedagógico na perspectiva da gestão democrática}

O projeto político-pedagógico é também chamado de proposta pedagógica (BRASIL, 1996), projeto pedagógico-curricular (LIBÂNEO; OLIVEIRA; TOSCHI, 2012) ou projeto pedagógico (GADOTTTI, 2000), diferentes termos utilizados para imprimir o mesmo sentido. O 
termo PPP carrega significados explícitos da indissociabilidade entre a dimensão política e pedagógica. A dimensão pedagógica expõe a relação entre as práticas educativas e a sociedade em geral, sendo pedagógico porque estrutura as ações educativas para que a escola desenvolva sua proposta. $\mathrm{Na}$ dimensão política "reside a possibilidade da efetivação da intencionalidade da escola, que é a formação do cidadão participativo, responsável, compromissado, crítico e criativo" (VEIGA, 2004, p. 15). É político porque exprime um compromisso social, com a formação do cidadão para um tipo de sociedade que se deseja.

A união dessas dimensões gera força ao PPP, uma vez que busca uma organização do trabalho pedagógico em sua abrangência, tornando-o, assim, o documento de maior referência para o coletivo escolar e a comunidade. Veiga (2004) concebe o PPP como a própria organização do trabalho pedagógico e, como tal, pode se desenvolver, na concepção de Freitas (1995), em dois níveis: no trabalho pedagógico da sala de aula e na organização do trabalho da escola.

O PPP é o "documento que apresenta as intenções, os objetivos, as aspirações de um processo de escolarização e inclui a proposta curricular" (LIBÂNEO; OLIVEIRA; TOSCHI, 2012, p. 426). Veiga (2004) o define como um projeto que reflete a realidade da escola, como um instrumento clarificador da ação educativa da escola em sua totalidade. Neste contexto, ele aponta uma direção, um compromisso, uma visão de mundo e de sociedade que deve ser pensada junto ao coletivo da escola. Esse é um processo de construção democrática que reflete e questiona qual é a função social da escola e o que ela poderá vir a ser.

Com efeito, é um trabalho que solicita o envolvimento do coletivo da escola, com a integração família, escola e comunidade, mediante formas democráticas de gestão articuladas ao compromisso sociopolítico da escola. A participação da comunidade é basilar para a democratização das relações de poder no interior da escola e a melhoria da qualidade de ensino, além de envolver um processo democrático de trabalho coletivo e inclusão em direção a mudanças significativas na forma de gestão (GADOTTI, 2000). Como ponderam Libâneo, Oliveira e Toschi (2012, p. 458), “a organização escolar democrática implica não só a participação na gestão, mas a gestão da participação". Por esse prisma, o da escola necessita operar sob as bases de uma concepção democrático-participativa que, conforme o referido autor, baseia-se na: relação orgânica entre a direção e a participação dos membros da equipe; busca por objetivos comuns assumidos por todos, decisões tomadas coletivamente, e cada membro assumi sua parte no trabalho.

Essa concepção defende que cada pessoa participe das discussões e decisões e assuma seus deveres e responsabilidades. Nesta direção, as Diretrizes Curriculares Nacionais (DCNs) 
alegam que para alcançar autonomia é necessário que cada escola construa sua identidade ancorada no PPP de forma democrática, ou seja, em parceria com a comunidade. As DCNs reconhecem a relevância da autonomia da escola. Para ser autônoma, necessário se faz realizar mudanças na organização do trabalho pedagógico, com formas democráticas para se pensar as finalidades sociais, políticas e culturais da escola. Sua concretização determina que o compromisso seja assumido por todos os atores educativos. O processo participativo demanda a articulação entre escola-família-comunidade com sua própria história, cultura e diferenças, valorizando, desta maneira, sua identidade. A construção do PPP clama pela presença do coordenador pedagógico como articulador para instituir uma gestão democrático-participativa na escola.

Não obstante, em muitas escolas esse documento é tratado apenas como um instrumento para atender as exigências burocráticas. É o que se percebe nos estudos de Libâneo, Oliveira e Toschi (2012), ao considerarem a:

\begin{abstract}
Efetivação da prática de formulação coletiva do projeto pedagógico ainda é, na maior parte dos casos, bastante precária. Vigora mais como um princípio educativo do que como um instrumento concreto de mudanças institucionais e de mudanças no comportamento e das práticas dos professores. Em boa parte das escolas, predomina o modelo burocrático de gestão: decisões centralizadas, falta de espírito de equipe, docentes ocupados apenas com suas atividades de aula, relações entre professores e alunos ainda formais e regidas por regras disciplinares (LIBÂNEO; OLIVEIRA; TOSCHI, 2012, p. 483).
\end{abstract}

Pensar o PPP da escola requer apontar algumas questões que permeiam sua constituição, tais como: ser o condutor das formas de OTP de sala de aula e da escola e orientar os processos de planejamento de ensino, curricular e o plano de aula. É por intermédio do PPP que os docentes ressignificam suas experiências, refletem sua prática e sua realidade, resgatam, reafirmam e atualizam conhecimentos.

Como elemento essencial do trabalho do coordenador pedagógico, o PPP pode promover mudanças, dado que identifica saberes, visões de mundo, de educação e de conhecimentos, dando sentido aos projetos individuais e coletivos, no contínuo movimento de (re)afirmação das identidades. Principalmente ao estabelecer novas relações de convivência e indicar novos caminhos, possibilidades e propostas de ação.

Ressalta-se que o PPP se caracteriza como um projeto de vida que tem sua base imersa na sociedade, nos objetivos e nas finalidades educacionais que se visa construir e transformar. Esse projeto é assegurado pela $\mathrm{LDB} / 96$, ao afirmar, no artigo 12, que os estabelecimentos de ensino devem elaborar e executar suas próprias propostas pedagógicas. Por esse caminho, inclui-se o artigo 13 ao inferir que os docentes devem participar dessa elaboração e colaborar com as atividades de articulação da escola com as famílias e a comunidade (BRASIL, 1996). 
É fato que, apesar de a LDB/96 determinar que cada escola construa a sua proposta pedagógica, isso não é suficiente para garantir um processo democrático e um ensino de qualidade. Embora o PPP abranja as ações planejadas em consonância com as diretrizes educacionais, levando em consideração as políticas filosóficas da escola e as intenções para sua transformação, sabe-se que sua construção e implementação são um enorme desafio para o coordenador pedagógico. É um processo complexo de mudanças na forma de pensar, planejar e organizar o trabalho pedagógico na contramão de práticas individualistas e descomprometidas, tanto da coordenação pedagógico quanto dos professores.

Esse é um dos grandes desafios: trabalhar coletivamente, porque, segundo Gadotti (2000), há pouca experiência democrática, prevalência das práticas de autoritarismo e estrutura verticalizada dos sistemas educacionais. O problema é que os docentes, a coordenação e a direção pouco dialogam sobre as concepções filosóficas, sociais e políticas da escola com os discentes, e estes não se incomodam por desconhecê-los. Esse distanciamento revela a necessidade de compreensão da totalidade do ensino como processo. A educação é um todo, no qual o PPP e o trabalho do coordenador pedagógico se integram de maneira que se completam.

Para superar essa dificuldade, o pesquisador propõe o desenvolvimento da consciência crítica, o envolvimento das pessoas, a participação e cooperação das várias esferas do governo e a autonomia, responsabilidade e criatividade como processo e produto do projeto (GADOTTI, 2000).

Superar essas dificuldades significa estar pronto para responder aos desafios do mundo contemporâneo, estar aberto a mudanças de gestão e organização do trabalho e, sobretudo, buscar o comprometimento e a cooperação de todos os atores educativos. Assim, o PPP deve ser considerado como um instrumento de debate dos problemas da escola e da realidade sociocultural.

Trata-se, portanto, de um instrumento de gestão democrática, de debate, organização, interação e articulação do trabalho pedagógico que necessita ser constantemente reconstruído. $\mathrm{O}$ coordenador pedagógico, ao reavaliar o PPP, juntamente com os professores, torna o processo mais democrático, planejado e configurado dentro de uma proposta que permite rever historicamente a função social da escola. O coordenador representa o implementador desse processo de gestão, pois uma das suas principais atribuições é a de participar ativamente na construção, implementação, no desenvolvimento e na avalição do PPP da escola. 


\section{$4 \mathrm{O}$ que dizem os coordenadores pedagógicos e os projetos político-pedagógicos: atribuições e metas}

Dentre outras atribuições, um coordenador pedagógico promove conhecimento, orienta os projetos, aproxima os professores um dos outros, os estudantes dos professores e a escola da comunidade. Sendo assim, é preciso que o coordenador pedagógico seja consciente do seu papel, das suas atribuições dentro da escola e dos desafios do cotidiano do seu trabalho. Para além de articulador do PPP, seu objetivo consiste em apoiar os professores na compreensão de sua prática e das dificuldades diárias. Ele precisa ter a "convicção de que qualquer situação educativa é complexa, permeada por conflitos de valores e perspectivas, carregando um forte componente axiológico e ético, o que demanda um trabalho integrado, integrador, com clareza de objetivos" (FRANCO, 2008, p. 120).

No processo de coleta de dados, realizaram-se entrevistas, tendo como sujeitos do conhecimento três coordenadores pedagógicos da rede pública de ensino do Distrito Federal, para os quais se indagou sobre suas atribuições enquanto coordenadoras pedagógicas do Ensino Fundamental.

A coordenadora pedagógica da Escola A relatou que suas atribuições incluem "um trabalho de mediação entre os professores, as práticas educativas e a comunidade”. Já a coordenadora pedagógica da Escola B comentou que sua função "é a de ser um apoio aos professores, que orienta e direciona o trabalho como um todo". A coordenadora salienta que busca realizar um trabalho em equipe com a participação dos professores nas tomadas de decisões. Por fim, a coordenadora da Escola C alegou que sua principal atribuição é"organizar e direcionar o trabalho pedagógico da escola com dialogicidade e participação dos professores".

Percebe-se, nos depoimentos, que o coordenador pedagógico representa um profissional de apoio que ajuda os professores, o que indica uma simplificação das suas atribuições. Não foi explicado de que forma essa mediação, esse apoio e direcionamento acontecem, tampouco foi mencionada qualquer atividade de formação continuada. Consoante analisa Lima e Santos (2007, p. 78), entende-se que o papel do coordenador pedagógico vai muito além de articulador, é o “agente responsável pela formação continuada de professores".

Para além do que declaram os coordenadores pedagógicos, suas atribuições abarcam uma variedade de atividades diárias. É o que se verifica no projeto político-pedagógico das Escolas A e C. 
Quadro 1 - Atribuições do coordenador pedagógico (2018)

\begin{tabular}{|c|l|}
\hline \multirow{2}{*}{ Escola A } & $\begin{array}{l}\text { - Elaborar o plano de ação das atividades de coordenação pedagógica; } \\
\text { - Participar da elaboração, implementação, do acompanhamento e da avaliação do PPP; } \\
\text { - Orientar e coordenar a participação docente nas fases de elaboração, execução, } \\
\text { implementação e avaliação da organização curricular; } \\
\text { - Articular ações pedagógicas entre os diversos segmentos da escola e a coordenação regional } \\
\text { de ensino; } \\
\text { - Divulgar e incentivar a participação do professor em todas as ações pedagógicas promovidas } \\
\text { pela Secretaria de Estado de Educação do Distrito Federal; } \\
\text { - Estimular, orientar e acompanhar o trabalho docente na implementação do currículo da } \\
\text { educação básica e das orientações pedagógicas por meio de pesquisas, estudos individuais e } \\
\text { em equipe e de oficinas, assegurando a coordenação pedagógica como espaço de formação } \\
\text { continuada; } \\
\text { - Divulgar, estimular e apoiar o uso de recursos tecnológicos na escola; } \\
\text { - Articular os três níveis de avaliação com vistas à melhoria do processo de ensino- } \\
\text { aprendizagem. }\end{array}$ \\
\hline
\end{tabular}

Fonte: Projeto político-pedagógico das Escolas A e C de 2018.

As atribuições do coordenador pedagógico descritas no PPP das escolas A e C são iguais, o que sugere pouca atenção dada às atribuições do CP e, por conseguinte, ao constante processo de reflexão e consolidação das práticas pedagógicas coletivas. Ademais, o fato de as atribuições serem cópia uma da outra demonstra que nenhuma alteração foi realizada de um ano para outro, já que são duas escolas com realidades e contextos diferentes.

Por mais que as atribuições dos coordenadores pedagógicos possam ser estabelecidas de forma geral, elas obedecem às necessidades e peculiaridades específicas de cada escola. Como lembra Gadotti (2000, p. 36), “o projeto pedagógico da escola está hoje inserido num cenário marcado pela diversidade [...]. Não existem duas escolas iguais".

Como o PPP da Escola B não apresenta atribuições do coordenador pedagógico, este sinaliza que o trabalho por ele desenvolvido não é tão significativo. Apesar da complexidade que envolve a função de coordenação pedagógica, pressupõe-se uma falta de clareza nas definições e atribuições do coordenador pedagógico, ou seja, as determinações explícitas e implícitas do trabalho do coordenador pedagógico anunciam certa dificuldade em determinar sua própria função.

Dessa maneira, o trabalho do coordenador pedagógico requer um amplo debate e estudo acerca das suas funções frente as demandas da escola. Isso fortalece o reconhecimento do PPP como elemento que subsidia os projetos, as atividades e práticas pedagógicas para uma educação continuada que contribua para a formação crítico-reflexiva do docente e do estudante. Antes de 
reconhecer os projetos educativos que fazem parte do currículo escolar, é vital conhecer claramente o PPP da escola, sua realidade e particularidades.

Quadro 2 - As contribuições das coordenadoras sobre o PPP

\begin{tabular}{|l|l|}
\hline \multirow{2}{*}{ Coordenadora A } & $\begin{array}{l}\text { O PPP é muito mais que um documento, é o caminho para a mudança da realidade; } \\
\text { Todas as ações propostas no PPP são orientandas e acompanhadas; sem o PPP, esse } \\
\text { trabalho não teria um objetivo comum. }\end{array}$ \\
\hline Coordenadora B & $\begin{array}{l}\text { - É o PPP que torna meu trabalho possível; } \\
\text { - Oriento minhas atividades pelo plano de ação. }\end{array}$ \\
\hline Coordenadora C & $\begin{array}{l}\text { - É por ele que eu realizo meu trabalho; } \\
\text { Apresenta toda ação intencional e compromisso coletivo da escola que deve ser } \\
\text { orientada pela coordenação. }\end{array}$ \\
\hline
\end{tabular}

Fonte: Entrevista coletada com as coordenadoras pedagógicas.

Essa análise vai ao encontro do depoimento das coordenadoras pedagógicas ao ratificarem dois pontos: a importância do PPP para seu trabalho e a conscientização de um trabalho construído no âmbito coletivo, de forma democrática. As falas demonstram que o PPP representa o principal documento que torna possível a realização das tarefas diárias. As respostas das entrevistadas foram próximas umas das outras na explicação de que o PPP é utilizado pelo coordenador para direcionar suas ações de acordo com as propostas, com vistas a alcançar os objetivos da escola como um todo.

Sobre a segunda constatação, ressoa-se a conscientização de um trabalho coletivo. Notase que esse é um trabalho realizado no cotidiano da escola, na discussão dos problemas e desafios e na definição de propostas curriculares e avaliativas. Deste modo, a implementação de um trabalho coletivo não aparece como um imperativo natural, mas sim no debate e nas respostas frente a uma problemática que somente se efetiva pela participação de todos, por suas interações e decisões coletivas (LIMA; SANTOS, 2007).

Para as pesquisadoras Silva e Fernandes (2017), a coordenação pedagógica é o espaçotempo de planejamento do trabalho pedagógico, num processo coletivo de tomada de decisões. As autoras reforçam que

Compete aos coordenadores pedagógicos, em conjunto com a equipe de direção, a elaboração do plano de ação da coordenação pedagógica, caracterizando a ação coordenadora como trabalho conjunto entre eles próprios, e não somente como acompanhamento dos professor. Esse plano de ação elaborado com base no projeto político-pedagógico da escola possibilita aos coordenadores articulem o trabalho pedagógico com qualidade (SILVA; FERNANDES, 2017, p. 78).

Por essa asserção, vale destacar dois pontos: a atribuição do coordenador pedagógico como articulador do trabalho pedagógico coletivo, como também a (re)construção de seu próprio plano de ação sob as premissas do PPP e sob a colaboração de outros profissionais, diretores e 
coordenadores de áreas. O plano de ação traça as metas que se deseja alcançar e, para elaborá-lo, o coordenador pedagógico precisa conhecer profundamente o PPP e o regimento da escola que trabalha.

Quadro 3 - Metas do Plano de Ação da coordenação pedagógica (2018)

Escola A - Metas do plano de ação da coordenação pedagógica:

- Assessorar o trabalho do professor;

- Realizar estudos pedagógicos oportunizando a formação continuada dos professores;

- Oferecer oficinas com a utilização de materiais concretos;

- Propor e orientar atividades que resgatem valores, hábitos e atitudes;

- Elaborar e planejar a execução dos projetos;

- Conduzir o trabalho do grupo a partir de uma mesma perspectiva de ensino;

- Planejar ações que envolvam a participação direta da comunidade escolar nos eventos e demais trabalhos da escola.

Escola B - Metas do plano de ação da coordenação pedagógica:

- Articular e promover a formação continuada dos professores;

- Desenvolver os projetos propostos no PPP;

- Minimizar as dificuldades de aprendizagem;

- Promover debates, oficinas e trocas de experiências;

- Dar suporte na organização das atividades pedagógicas.

Escola C - Metas do plano de ação da coordenadora pedagógica:

- Ppromoção de estudos e atividades de formação continuada norteando o trabalho pedagógico do professor;

- Planejamento de rotinas de trabalho;

- Acompanhamento das atividades pedagógicas e da aprendizagem dos alunos;

- Busca por parcerias para atividades pedagógicas;

- Construção coletiva dos reagrupamentos e do projeto interventivo;

- Apresentação dos indicadores do desempenho da escola para reflexão;

- Estudo do regimento escolar;

- Realização de oficina pedagógica;

- Participação nos conselhos de classe;

- Avaliação dos três níveis de avaliação;

- Incentivo ao uso do laboratório de informática.

Fonte: PPP das Escolas A, B e C de 2018.

A definição das metas do trabalho do coordenador pedagógico no plano de ação aparece descritas no PPP de cada uma das escolas. Entre todas as metas, pode-se identificar a unanimidade de uma questão: a promoção de estudos e atividades de formação contínua dos professores. Decorre-se daí a perspectiva de Silva e Fernandes (2017, p. 77), de que a coordenação pedagógica é também espaço e tempo de formação continuada, "em que os professores são atores ativos no processo formativo, assim como fortalece a articulação entre teoria e prática”. A preocupação com a formação continuada não aparece nas falas, entretanto, aparece no plano de ação das coordenadoras pedagógicas. A formação constante é um processo 
que depreende da reflexão sobre as práticas pedagógicas. Neste sentido, leva os professores a ressignificarem suas práticas, resgatando sua autonomia.

No Distrito Federal, a coordenação pedagógica, organizada com base na determinação da Secretaria do Estado de Educação, possui três horas diárias distribuídas na semana para formação continuada. Geralmente o dia destinado à coordenação pedagógica coletiva é as quartas-feiras, com estudos e reflexões conforme as necessidades dos professores e demais profissionais da escola. O tempo e o espaço da coordenação pedagógica instituída pela Secretaria não garantem um trabalho coletivo, por isso a relevância de um projeto social de transformação de formação continuada.

As metas do plano de ação elaboradas em consonância com os princípios do PPP da escola permitem que o trabalho do coordenador pedagógico tenha objetivos claros, oferecendo, assim, um trabalho coletivo mais coeso. É o que assevera Franco (2008, p. 128): “o coordenador pedagógico poderá fazer um bom trabalho no acompanhamento, na liderança das negociações do projeto em ação. Antes disso, sem um projeto esclarecedor de metas e anseios, ele nada poderá fazer". Portanto, um plano de ação ecoa um processo de organização e gestão com a definição das tarefas e caminhos a serem seguidos.

Isso significa um passo valoroso para que, a partir de uma gestão democrática, se tenha consciência dos problemas e das especificidades que surgem no espaço escolar e dos caminhos rumo às soluções, num movimento constante de reflexão crítica, constituindo-se um desafio para a escola como um todo. Por isso é necessário que o PPP da escola seja anualmente reformulado, uma vez que nele se estabelecem as metas da escola e do trabalho do coordenador pedagógico, que são dinâmicas e mutáveis.

A Portaria n. 29 de fevereiro de 2006, que dispõe sobre normas para a coordenação pedagógica na Rede Pública de Ensino, institui algumas ações. $O$ artigo $6^{\circ}$ define as responsabilidades e atribuições locais: implementação da proposta pedagógica; incentivo à participação nas ações de educação continuada; acompanhamento do trabalho docente e formulação de proposta para a reflexão avaliativa da equipe, com o objetivo de redimensionar o trabalho pedagógico. Para além dessas ações, outras atribuições são delineadas no interior das escolas, com vistas às especificidades locais, e nem sempre essas ações estão voltadas para o eixo norteador, que deve ser o PPP. 


\section{Para continuar as reflexões}

As metas do plano de ação do coordenador pedagógico, definidas pelas três escolas, contemplam pressupostos essenciais acerca do PPP, tais como: trabalho coletivo, formação continuada, gestão democrático-participativa, atribuições e metas do $\mathrm{CP}$, desenvolvimento de projetos e atividades, envolvimento da comunidade, entre outros. No entanto, os depoimentos não conseguem abranger o universo amplo de responsabilidades e atividades desempenhadas pelo coordenador pedagógico das escolas analisadas.

A partir do estudo realizado, verifica-se que há uma simplificação das atribuições do coordenador pedagógico. Embora as atribuições e metas estejam claras no plano de ação, estas não aparecem nas falas das coordenadoras. Diante disso, pode-se deduzir que as atribuições e metas do coordenador pedagógico necessitam de pesquisa, esclarecimento, aprofundamento de estudos sobre o trabalho desenvolvido, reflexão coletiva e compromisso por parte dos profissionais.

O PPP das escolas analisadas segue caminhos próximos na implementação de práticas coletivas. Os documentos orientam para a construção e o desenvolvimento de uma proposta pedagógica dinâmica, aberta ao diálogo e à valorização de todos. É o PPP que oferece subsídios para que a escola se torne um espaço de democratização e inclusão social. Sendo assim, o coordenador pedagógico comprometido com o trabalho pedagógico no seio de suas atribuições e planos de ação constitui agente de transformação do cotidiano escolar.

O papel indispensável do PPP é promover uma visão ampla, contextualizada e crítica da OTP da escola, incluindo as diferentes atribuições dos profissionais, da comunidade, dos professores, estudantes e coordenadores em geral. Isso significa que, apesar dos desafios de integração e participação de todos os professores na releitura e reelaboração do PPP, é preciso ter consciência de que o CP é o principal responsável pela implementação desse documento.

\section{Referências}

BRASIL. Lei n. 9.394, de 20 de dezembro de 1996. Estabelece as diretrizes e bases da educação nacional. Brasília, 1996.

BRASIL. Governo do Distrito Federal. Secretaria de Estado de Educação. Portaria n. 29 de 06 de fevereiro de 2006. 
BRASIL. Ministério da Educação. Secretaria de Educação Básica. Diretriz̧es Curriculares Nacionais Gerais da Educação Básica. Brasília, 2013.

FRANCO, Maria Amélia Santoro. Coordenação pedagógica: uma práxis em busca de sua identidade. Revista Múltiplas Leituras, v. 1, n. 1, p. 117-131, jan./jun. 2008.

FREITAS, Luiz Carlos de. Crítica da Organização do Trabalho Pedagógico e da Didática. Campinas: Papirus, 1995.

GADOTTI, Moacir. Perspectivas atuais da educação. Porto Alegre: Artes Médicas, 2000.

LIBÂNEO, José Carlos; OLIVEIRA, João Ferreira de; TOSCHI, Mirza Seabra. Educação escolar: políticas, estrutura e organização. São Paulo: Cortez, 2012.

LIMA, Paulo Gomes; SANTOS, Sandra Mendes dos. O coordenador pedagógico na educação básica: desafios e perspectivas. Educere et educar: Revista de Educaşão, v. 2, n. 4, p. 77-90, jul./dez. 2007.

SILVA, Edileuza Fernandes.; FERNANDES, Rosana César. Coordenação pedagógica: espaço e tempo de organização do trabalho pedagógico coletivo. In: VILLAS BOAS, B. (Org.). Avaliação: interações com o trabalho pedagógico. Campinas: Papirus, 2017.

VEIGA, Ilma Passos Alencastro. Educação Básica e Educação Superior. Projeto político-pedagógico. Campinas: Papirus, 2004.

Paranaenses.

Recebido em: 09 abr. 2019 / Aprovado em: 27 set. 2019

Cite como

BRISOLLA, Lívia Santos; DUTRA, Norivan Lustosa Lisboa. Projeto político-pedagógico da escola: o elemento essencial do trabalho do coordenador pedagógico. Dialogia, São Paulo, n. 33, p. 33-46, set./dez. 2019. Disponível em: https://doi.org/10.5585/Dialogia.n33.13496. 